\title{
The impact of dental status on perceived ability to eat certain foods, nutrient intake and nutritional status in older adults: UK National Diet and Nutrition Survey 2008-2012
}

\author{
S. Watson ${ }^{1}$, C.R. Cardwell ${ }^{1}$, J.V. Woodside ${ }^{1,2}$ and G. McKenna ${ }^{1,3}$ \\ ${ }^{1}$ Centre for Public Health, Queen's University Belfast, Belfast BT12 6BJ, UK, \\ ${ }^{2}$ Institute for Global Food Security, Queen's University Belfast, Belfast BT9 5BN, UK and \\ ${ }^{3}$ Centre for Dentistry, Queen's University Belfast, Belfast, Belfast BT12 6BP, UK
}

Food choice is influenced by many factors, including income, education and taste preferences. Dental status is an important factor, especially for older people ${ }^{(1)}$. As people get older they are more likely to lose their teeth, which may affect their ability to bite and chew certain foods. This often means important foods such as fruit and vegetables are avoided; consequently this may affect their nutritional status ${ }^{(1)}$. The aim is to examine how dental status affects perceived ability to eat to certain foods, nutrient intake and nutritional status in older adults in the UK.

The current analysis used data collected as part of the UK National Diet and Nutrition Survey (NDNS) 2008-2012, a crosssectional survey of dietary habits and nutritional status of a representative sample of children and adults. Only participants aged 65 years and over were included in the analysis $(n=425)$. A 4-day food diary assessed dietary intake, while socio-demographic and oral health information were collected by a Computer Assisted Personal Interview. Specifically participants were asked about their dental status, i.e. if they had any natural teeth (dentate) or not (edentate), and if they wore dentures. Participants were classified into three groups for analysis: edentate with dentures $(\mathrm{E}-\mathrm{DEN}, \mathrm{n}=109)$, dentate with dentures $(\mathrm{D}-\mathrm{DEN}, \mathrm{n}=126)$ or dentate with no dentures (DEN, $\mathrm{n}=190)$.

Logistic regression analysis was conducted to examine the association between dental status on perceived ability to eat (eat with some difficulty/could not eat all vs. no difficulty) 12 selected foods. Compared to the DEN group (reference), both the D-DEN and E-DEN groups were more likely to have difficulty eating crusty bread (OR [95 \%CI): $3 \cdot 14[1 \cdot 59,6 \cdot 20], \mathrm{P}=0 \cdot 001 \& 3.96[1 \cdot 98$, 7.92], $\mathrm{P}<0.001)$, well done steak $(2.90[1.56,5.38], \mathrm{P}=0.001 \& 5.48$ [2.92, 10.3], $\mathrm{P}<0.001)$, raw carrots $(3.08$ [1.70, 5.57], $\mathrm{P}$ $<0.001 \& 5.71[3 \cdot 12,10 \cdot 5], \mathrm{P}<0.001)$, apples $(2 \cdot 64$ [1.47, 4.76], $\mathrm{P}=0.001 \& 6 \cdot 67$ [3.67, 12.1], $\mathrm{P}<0 \cdot 001)$ and nuts $(2 \cdot 17$ [1.17, 4.02], $\mathrm{P}=0.014 \& 5.42[2.97,9.92], \mathrm{P}<0.001)$ after adjusting for age and gender.

After controlling for age, gender, socio-economic status (SES) and energy intake (kcal/d), the E-DEN group compared to the D-DEN group had lower mean daily intakes of protein $(67 \cdot 0 \pm 1.45$ vs. $71.8 \pm 1.29 \mathrm{~g} / \mathrm{d} ; \mathrm{P}=0.035)$, magnesium $(229 \cdot 3 \pm 5 \cdot 71$ vs. $255.0 \pm 5.07 \mathrm{mg} / \mathrm{d} ; \mathrm{P}=0.002)$ and potassium $(2686.8 \pm 57.2 \mathrm{vs} .2887 .6 \pm 50.8 \mathrm{mg} / \mathrm{d} ; \mathrm{P}=0.024)$, and had lower mean daily intakes of NSP $(12.7 \pm 0.43$ vs. $14.7 \pm 0.31 \mathrm{~g} / \mathrm{d} ; \mathrm{P}=0.001)$, folate $(243.7 \pm 8.65$ vs. $272.2 \pm 6.22 \mu \mathrm{g} / \mathrm{d} ; \mathrm{P}=0.024)$, iron $(9.66 \pm 0.26$ vs. $10.5 \pm$ $0.19 \mathrm{mg} / \mathrm{d} ; \mathrm{P}=0.038)$, magnesium $(229.3 \pm 5.71$ vs. $251.7 \pm 4.10 \mathrm{mg} / \mathrm{d} ; \mathrm{P}=0.005)$ and potassium $(2686 \cdot 8 \pm 57.2 \mathrm{vs} .28640 \cdot 0 \pm 41 \cdot 1$ $\mathrm{mg} / \mathrm{d} ; \mathrm{P}=0.039)$ compared to the DEN group. No differences in nutrient intakes were observed between the DEN and D-DEN groups.

\begin{tabular}{|c|c|c|c|c|c|c|c|}
\hline \multirow[b]{2}{*}{ Dietary recommendation } & \multirow[b]{2}{*}{ DEN } & \multicolumn{3}{|c|}{ D-DEN } & \multicolumn{3}{|c|}{ E-DEN } \\
\hline & & OR & $95 \% \mathrm{CI}$ & $\mathrm{P}$ & $\overline{\mathrm{OR}}$ & $95 \% \mathrm{CI}$ & $\mathrm{P}$ \\
\hline 5-a-day fruit \& vegetable & REF & $0 \cdot 82$ & $0 \cdot 51,1 \cdot 30$ & $0 \cdot 394$ & $0 \cdot 23$ & $0 \cdot 13,0.42$ & $<0.001$ \\
\hline $70 \mathrm{~g} / \mathrm{d} \mathrm{red} /$ processed meat & REF & $0 \cdot 51$ & $0 \cdot 31,0 \cdot 83$ & 0.007 & 0.56 & $0 \cdot 33,0.94$ & 0.030 \\
\hline $140 \mathrm{~g} / \mathrm{wk}$ oily fish & REF & 0.57 & $0 \cdot 34,0 \cdot 95$ & 0.032 & 0.41 & $0 \cdot 23,0 \cdot 75$ & 0.003 \\
\hline $18 \mathrm{~g} / \mathrm{d}$ NSP & REF & 0.72 & $0 \cdot 39,1 \cdot 35$ & $0 \cdot 307$ & 0.40 & $0 \cdot 18,0.88$ & 0.023 \\
\hline
\end{tabular}

Logistic regression analysis. Data are odd ratios (95\% CI). Adjusted for age, gender and energy intake (kcal/d).

The table above depicts the odds for achieving UK dietary recommendations according to dental status. The E-DEN group were less likely to meet the four dietary recommendations than the DEN group. The D-DEN group compared with the DEN group were less likely to achieve the red and processed meat, and the oily fish dietary recommendations.

Within this sample of older adults wearing dentures appears to affect perceived ability to eat certain foods. Furthermore, having no remaining natural teeth and wearing dentures appears to impact the intake of key nutrients, as well as prevent important dietary recommendations from being met.

1. Marcenes W, Steele JG, Sheiham A et al. (2003) Cad Saude Publica 19, 809-816. 